\title{
SOCIAL CONTRACTS, MARKETS AND EFFICIENCY: GROUNDWATER IRRIGATION IN NORTH INDIA
}

\author{
A. Banerji \\ Email: a.banerji@econdse.org \\ Department of Economics, Delhi School of Economics \\ Gauri Khanna \\ World Health Organization, Geneva \\ J. V. Meenakshi \\ Email: meena@econdse.org \\ Department of Economics, Delhi School of Economics
}

\section{Working Paper No. 183}

Centre for Development Economics

Department of Economics, Delhi School of Economics 


\title{
SOCIAL CONTRACTS, MARKETS AND EFFICIENCY: GROUNDWATER IRRIGATION IN NORTH INDIA
}

\author{
A. Banerji , Gauri Khanna and J.V. Meenakshi
}

\begin{abstract}
This paper uses primary data to analyze the institutions and informal markets that govern groundwater allocation in the principal sugarcane belt of North India. In contrast to earlier literature, we find that the observed water trades result in efficient water allocation across farms. We interpret this and other stylized facts in terms of a simple bargaining model with limited inter-player transfers. Poor functioning of the power sector leads to reduced pumping and a water supply constraint. Simulations show that power supply reform can significantly increase farm yields, be financed out of the increased farm profits, and provide an instrument to use for attaining intertemporal efficiency in water allocation.
\end{abstract}

Key Words: water markets, market structure, water production function.

JEL Classification Codes: L1, Q1, Q2.

\section{ACKNOWLEDGEMENTS}

We thank the South Asian Network for Development and Environmental Economics (SANDEE) for funding this project, Ajay Kumar for research and field work assistance, Rajpal Singh for field work, R.P. Singh and D.R. Singh for help with logistics, Ch. Ranjit Singh's family for their hospitality, the National Bureau of Soil Surveys and Land Use Planning and the Water Technology Centre at the Indian Agricultural Research Institute for help with soil analysis and discharge measurement respectively. We thank Partha Dasgupta, E. Somanathan, Enamul Haque, Nirmal Sengupta, Priya Shyamsundar, Tushaar Shah, Rohini Somanathan, for comments on an early version of this paper; and Mausumi Das, Hemanshu Kumar, L. Kumawat, Navdeep Sahni and participants at a SANDEE Workshop for helpful suggestions.

This is a substantially revised and updated version of an earlier Centre for Development Economics Working Paper (No. 152, 2006).

'Delhi School of Economics, University of Delhi, India. Email: a.banerji@econdse.org

* World Health Organization, Geneva

`Delhi School of Economics, University of Delhi. Email: meena@econdse.org 


\section{SOCIAL CONTRACTS, MARKETS AND EFFICIENCY: GROUNDWATER IRRIGATION IN NORTH INDIA}

\section{Introduction}

Amidst rapidly growing economic activity in India, there are increasing concerns of water scarcity, and of declining groundwater tables in particular. In North India, successful agricultural growth in the past few decades has been accompanied by a massive expansion of groundwater irrigation. The popularity of water intensive crops (such as rice and sugarcane) is said to be responsible for decreasing groundwater tables, raising concerns about the efficiency and sustainability of groundwater use. This has in turn given rise to a debate on whether market institutions for water engender optimal and/or equitable water allocations, and, relatedly, on the role of the widely prevalent system of flat-rate (lump sum) electricity pricing in contributing to inefficient water use in agriculture.

These concerns provide the backdrop for the present study, which characterizes the institutions that govern water allocation in a typical village setting in North India with deep and declining water tables, and draws inferences for the design of instruments that may facilitate efficient water use. In particular, we examine whether the informal water markets that operate in this village economy are monopolistic in nature and therefore lead to inefficient outcomes, as is argued in much of the literature. We conclude that the water trading that we observe is better viewed as part of a social contract; and that this contract results in a spatially efficient allocation of water.

Next, based on our characterization of the water transactions in this village, we use simulations to analyze the impact of an electricity pricing and delivery regime different than the 
present one, on yields and on the sustainability of water use. We find that policy reform in the power sector can significantly improve crop yields by allowing farmers to control the volume and timing of irrigations. Related work beyond this paper shows that such reform can enable pricing electricity in order that pumping groundwater is implicitly taxed, at a rate that delivers intertemporally efficient water use. Thus we argue that the policy focus should shift from worries about water allocation within villages to policy reform in pricing and delivering electricity that powers groundwater extraction.

The paper is based on data collected in a primary survey in Tabelagarhi, a village located in the sugarcane belt in Western Uttar Pradesh, India. The survey was carried out over an entire crop-cycle of about a year in 2004-05.

The broad North Indian agricultural belt has a water economy that shares the institutional features observed in Tabelagarhi. These include predominant or exclusive use of groundwater for irrigation, and a low and declining water table that makes it uneconomical to use diesel to fuel the pumps that run tubewells. The pumps thus use electricity to draw water from depths of 70 feet and below. However, cultivation is heavily influenced by the erratic and inadequate State supplied electricity; this translates into inadequacy in the supply of irrigation water. As a consequence, cultivation is also adversely affected (e.g. Pant, 2004).

Further, fragmented landholdings, wide variation in plot sizes, and the high costs of boring wells and installing pumps imply that many plots, particularly smaller ones, do not have tubewells. As a result, purchase of water from informal markets is common.

Finally, in this region, a uniform water price per hour of tubewell use is set in an informal village-level agreement at the beginning of the season. This price does not vary across the season in response to varying power (and therefore water) availability, to clear the market. 
Consequently, water selling farmers can only adjust the quantity of water sales over the season. Even though tubewells service only nearby plots to prevent seepage losses from unlined channels, we do not find evidence of monopoly power; we argue below that using traditional categories of market structure to explain water sales from tubewell owners is not illuminating.

While details are set out in subsequent sections, we provide here a brief preview of our results. We find:

(i) Direct evidence that power shortage rations water supply.

(ii) The water shortage results in the marginal value product of water (MVPW) on tubewell owners' plots being significantly higher than the water price they get from selling water. A water price-taking, profit maximizing tubewell owner should then prefer, on the margin, to add water to his own plots rather than sell water.

(iii) Yet, tubewell owners sell significant quantities of water. We conclude that models that treat tubewell owners as profit-maximizing water-selling 'firms' are an inadequate description of the sugarcane belt of North India, at least. Instead, we infer, and model, the existence of a social contract, that determines both water price as well as water allocation across plots in the village. The contract is a response to fragmented holdings and the high cost of boring wells and installing pumpsets; this induces farmers to irrigate their multiple plots with a combination of own tubewells and water purchased from others' tubewells.

(iv) In fact, the social contract results in a spatially-efficient allocation of water: that is, reallocating the available water across plots would not increase output by much. This is a striking result, standing in sharp contrast with much of the literature, (such as Shah (1993), Meinzen-Dick (1996), and Jacoby, Murgai and Rahman (2004)) which 
has tended to find allocative inefficiency and attributed it to the presence of monopoly power of tubewell owners.

(v) However, notwithstanding the social contract, inadequate power extracts a toll. In simulations that provide a lower bound, we show that in the presence of adequate electricity, simulated yields are up to $9 \%$ higher than sample yields. Inadequate power supply is largely a consequence of the present system of a flat electricity charge unrelated to the quantum of electricity used. We find that unit pricing to cover the marginal cost of power is more expensive, but the reliable power supply that results induces increased yields and farm profits that can more than pay for such pricing.

(vi) Questions of sustainable groundwater use in this region are closely connected with those of intertemporal efficiency of water extraction from an aquifer with recharge. We cannot directly address intertemporal issues; however, our analysis shows that since water is in effect rationed at present, simulated irrigation volumes even with substantially higher electricity prices are $6 \%$ to $12.5 \%$ greater than in the sample, implying a somewhat higher rate of aquifer depletion. We briefly refer to some of our related work that provides estimates of markups on the economic cost of electricity that can lead to intertemporally efficient water use.

This study contributes to the substantial literature that examines questions of groundwater market structure, water allocation and attending issues related to efficiency and equity in South Asia, which includes, in addition to Jacoby, Murgai and Rahman (2004), Shah (1993) and Meinzen-Dick (1996) cited above, Palmer-Jones (1994), Dhawan (1995), Meinzen-Dick (2000), Sengupta (2000), Dubash (2002), Foster and Rosenzweig (2005) ${ }^{1}$. While informative on many issues, none of them contains the kind of estimation required to quantify the extent of water 
misallocation and simulate alternative policy environments, as we do in the present paper. Many of them measure price-cost margins for water, but do not structurally estimate its demand and supply. In fact, we show that using a price-cost margin for water extraction as an indicator of the extent of allocative inefficiency can be misleading, in a setting where tubewell owners are themselves water users, and water is rationed. Also, none of the studies above on India measures water prices volumetrically, making comparisons of even basic information such as marginal values of water difficult; (a recent exception is Somanathan and Ravindranath (2006)). Finally, unlike much of the literature, this paper models and finds empirical support for the existence of a social contract that governs water transactions; our analysis of its efficiency can inform the debate about the nature of local institutions in other environmental and development contexts.

The rest of the paper is organized as follows. Section 2 describes the study area and the data. Section 3 analyzes the water allocation across plots observed in the data, and provides evidence of widespread water rationing. It then argues that observing water sales in the presence of such rationing points to the existence of a social contract governing water transactions. Section 4 proposes a simple model of this social contract, which predicts, among other things, that water allocation across plots will be efficient. Section 5.1 analyzes the data to show that allocative efficiency is a good approximation of the village water economy. Section 5.2 discusses simulations that quantify the effect of a comprehensive change in power policy involving unitpricing of electricity. Section 6 concludes.

${ }^{1}$ See Schoengold and Zilberman (2005) for an excellent survey on the economics of water. 


\section{Village Survey and Stylized Facts}

\subsection{Survey}

Our analysis is based on a detailed village-level survey we conducted over the course of ten months. Our study site is Tabelagarhi village, in Baghpat district, selected from a 'dark' block $^{2}$ in the sugarcane belt of Western Uttar Pradesh ${ }^{3}$. By and large groundwater is the only source of irrigation for crops grown in this area, and the water table in this area has witnessed a steady decline over the last few decades.

Tabelagarhi has 165 cultivating households, all of whom cultivate sugarcane. The crop is irrigation intensive, requiring one irrigation pre-sowing, and regular irrigations thereafter. To construct our sample, we first conducted a census of all households and tubewells in the village. We then took a random sample of 73 tubewells (out of a village total of about 110), chosen primarily from the main cultivating areas north and east of the village, roughly in proportion to the total numbers of tubewells located in those directions. We identified all the plots serviced by these tubewells; these plots belong to 105 farmers. We then built the sample so that all 326 plots cultivated by these 105 farmers were included. Including all plots serviced by a tubewell implies that we can compute the total amount of water discharged by each tubewell over the season, from plot-level irrigation data; we also obtain, for each tubewell, the entire water allocation from it to various plots. This enables us to pose counterfactuals about the effect of reallocating this volume of water across plots serviced by each tubewell.

Data were collected at three levels: tubewell, plot, and farm household. Tubewell data (including the depth of the tubewell, capacity of the motor, tubewell discharge, maintenance costs and history) helps to estimate water supply characteristics. Plot-specific data (including

\footnotetext{
${ }^{2}$ Dark blocks are defined as areas where the quantum of groundwater used exceeds $85 \%$ of recharge.

${ }^{3}$ Sugarcane and rice are the two most water intensive crops widely cultivated in North India.
} 
details on source of irrigation, date of each irrigation, the number of hours the pumpset was run to deliver water, the terms of the water transaction, information on labor and other inputs, and soil quality) is needed to estimate the demand for irrigation water. Farm household data (including information on household members, and their education levels, and farm assets) can potentially help to identify farmer-specific effects on production. Field work was conducted once every two to three weeks, over the entire sugarcane cycle (2004-2005). This frequency corresponded to the pattern of irrigations; and given the large number of plots to be tracked, helped in keeping the recall period low ${ }^{4}$.

\subsection{Principal Features of the Study Village}

The village, as is the norm in Western Uttar Pradesh, is subject to erratic power supply. In May, power supply averaged 6-7 hours a day, this went up to 8-10 hours in June, and came down to 3-5 hours in July (these three months saw no rainfall). Conversations with experts and farmers at the site indicate that pre-monsoon irrigations are particularly crucial for plant growth. In 2004, the monsoon was delayed, and there was no rain in June and July. In this situation, one irrigation every 20 days was desirable. The lack of regular electricity supply meant that for those who irrigated using purchased water, irrigation got delayed due to poor power supply as priority was given to plots on which tubewells were situated.

(1).Water transactions, Fragmented Holdings, and the Pattern of Irrigation: All 73 tubewells in our sample run on electricity, but vary significantly in the technology employed to lift water. In particular, 29 of the pumpsets are 'submersible' and the rest are 'non-submersible.'

\footnotetext{
${ }^{4}$ We obtained assistance from the Water Technology Centre, Indian Agricultural Research Institute for determining irrigation volumes, and from the National Bureau of Soil Surveys and Land Use Planning in collecting and analyzing soil samples.
} 
Submersible pumps are much more expensive to purchase ${ }^{5}$. For areas with low water tables, they are however the desired technology to possess. As shown in Table 1.1, on average for our sample, a submersible takes approximately 90 minutes to irrigate one bigha (1 bigha roughly equals one-fifth of an acre), whereas a non-submersible takes about 2 hours. The costs of operating tubewells include the cost of electricity and maintenance costs. Electricity cost is an annual charge, based on the horsepower of the pump (Rupees 70 per month per horsepower). Submersibles not only have higher discharges, but are less prone to break-downs and have lower maintenance costs.

Table 1.2 presents the pattern of irrigation, contrasting plots that are served by purchased water, with those using their own tubewells. The average plot size in the two categories is 8.7 and 4.7 bighas respectively, so that plots that rely on purchased water are much smaller than those that use an owned tubewell. The overall number of irrigations favors plots that were watered through an owned tubewell; fewer irrigations were given to plots which rely on purchased water. More than the number of irrigations, their timing is crucial for plant growth. A key indication that plots that purchased water could not time their irrigations as well as others is the fact that in the dry summer months, a much lower percentage of these plots managed to complete the recommended 5 irrigations.

As in much of India, a common feature of the village is the fragmentation of farmers' holdings. There are about 3 plots per farmer, on average; these are typically located in 2 (and sometimes more) non-contiguous fragments. Farmers generally do not install tubewells on all of their plots and participate on both sides of the water market. In the sample, $92 \%$ of the farmers who

\footnotetext{
${ }^{5}$ A submersible pump has a hermetically-sealed motor, is submerged in the water, and has a greater lifting force as it does not rely on external air pressure for lifting water.
} 
purchased water to irrigate one or more plots, also sold water from a tubewell located on one of their other plots.

(2). Price of Water: A water price is set at the beginning of the season, as a result of a social consensus. The price is set in rupees per hour of use of a tubewell (Rs.15/hour in the data set), and holds for all water transactions in the village over the entire season; water buyers and sellers are price takers subsequent to this price being set. This apparent uniformity of prices has been noted elsewhere, and is cited as evidence that prices are determined as an outcome of a social contract. $^{6}$

We calculate the price of water per unit volume charged by a tubewell by dividing Rs. 15 by the measured volume of water that the tubewell discharges per hour. While the average price per bigha-inch (about 20.56 cubic meters) of water across all tubewells is Rs.6.50, ${ }^{7}$ variation in tubewell discharge translates into substantial variation around this mean, with the $25^{\text {th }}$ and $75^{\text {th }}$ percentiles being Rs. 4.70 and 8 respectively. Submersible pumps discharge much more water than non-submersibles, so the volumetric prices of water from tubewells with submersibles are significantly lower.

(3). Sugarcane Yields, Soil Quality and Other Inputs: Table 1.3 summarizes yields of sugarcane by category of plot, to examine whether the pattern of irrigation volume and timing is reflected in differential yields. As one might expect given the summary statistics on irrigation, yields are lower on plots with purchased water but the differences are not substantial.

These differences in yields are, of course, mediated not just by the amount of irrigation, but by soil quality and other inputs as well. As noted earlier, soil samples were collected from

\footnotetext{
${ }^{6}$ See for example Dubash (2002).
} 
each plot (from different corners and then mixed) and analyzed. The soils in these areas are of good quality; about two-thirds of the plots in Tabelagarhi may be classified as "sandy loam", and another $22 \%$ as loam, ${ }^{8}$ but the difference in yields between the two categories of plots is not large.

Summary statistics for the other major inputs are presented in Table 2. With labor, all activities are summed across by type of activity (land preparation and sowing, weeding and digging, applications of irrigation and other inputs, tying of cane, harvesting) and by type of labor (hired casual labor and permanent labor, contractual labor, household labor, labor in exchange and other miscellaneous forms). Aggregate labor use by category of plot suggests that plots which purchase water are slightly more labor intensive.

Tractors are primarily used at the time of pre-sowing for land preparation, and for sowing. Oxen are also used for these activities; in addition, they are used for transporting sugarcane to sugar depots at harvest time. While oxen were used on almost all plots, tractors were used on about half of them. Tractors tend to be used on the larger-sized plots.

\section{Water Allocation Across Plots}

We investigate two questions related to the water allocation across plots observed in our sample - whether water is rationed, and whether its allocation across plots is inefficient. We discuss mainly the evidence on the first question in this section, leaving a detailed exploration of allocative efficiency for Section 5.

\footnotetext{
${ }^{7}$ By way of comparison, this is a little greater than half of the average water price that Somanathan and Ravindranath (2006) estimate for water transactions in the Papagni watershed in the southern states of Andhra Pradesh and Karnataka.

8 Loamy soils are better, as they contain sand and silt in proportionate amounts, and are well drained. In contrast sandy loam soils are worse, in that these are coarse-textured, and typically require more irrigations. The remaining $10 \%$ of the plots are classified as clay loam, loamy sand, and silt loam. In terms of productivity, however, the impact of soil quality is discernible, if at all, only for plots using bought water, where yields on loam soils are 6 quintal per bigha higher than on sandy loam soils.
} 
3.1 Evidence of water rationing: Since electricity for pumping water is in short supply, it is possible that that there is quantity rationing of water on plots, as the price of water is fixed for the season. We use therefore the following natural notion of water rationing, (one which is also consistent with our model of Section 4). A water buying plot $i$ is water rationed if its MVPW exceeds the marginal cost of water extraction: i.e. if $p_{s} \hat{a}_{i}>\hat{c}_{t}$, where $\hat{c}_{t}$ is the estimated unit cost of water extraction for the tubewell supplying plot $i, p_{s}$ is the sugarcane price, and $\hat{a}_{i}$ is the estimated MPW (marginal product of water) for the plot. In order to make an inference about the existence of a social contract, we also compare the MVPW on a plot with the water price: i.e. whether for plot $i p_{s} \hat{a}_{i}>(<) q_{i J}$; where $q_{i J}$ is the water price for the plot (equal to the per hour village water price divided by the discharge of the tubewell which supplies plot $i$ ).

We estimate plot-level marginal product of water as the partial derivative of an estimated production function with respect to the water input on the plot; to determine whether rationing is significant, we derive a confidence interval around the MPW using asymptotic theory (see Appendix). Separately, we estimate the unit cost of water extraction from each tubewell.

\section{(1). Estimating the sugarcane production technology and unit costs of water extraction:}

The estimation of a production function is facilitated by the considerable variation in inputs across plots, owing to variation in plot sizes, in volumetric water prices (as discharge rates vary across tubewells), and some variation in other input prices. As farmers in the data set have multiple plots, we use farmer dummies to deal with identification problems caused by unobserved, farmer-specific shocks. ${ }^{9}$ We therefore estimate the equation

\footnotetext{
${ }^{9}$ See Marschak and Andrews (1944), Griliches and Mairesse (1998), Olley and Pakes (1996) and Levinsohn and Petrin (2003) on identification of production functions. Any production function estimation is susceptible to endogeneity, as the right-hand variables are objects of choice; these choices can depend on unobserved farmerspecific and plot-specific characteristics and thus be correlated with the error term. Multiple plots per farmer enable us to to control for the former with a farmer-specific fixed effect. We also have detailed plot-specific soil quality data to control for the latter. In our empirical work, we found that conditional upon farmer-specific dummies,
} 


$$
y_{i}=f\left(x_{i}, \beta\right) b_{t} \varepsilon_{i}
$$

where $b_{t}$ is a farmer $t$-specific shock unobserved by the econometrician (farmer $t$ cultivates plot i), which we can estimate using a dummy for farmer $t ; y_{i}, x_{i}, \varepsilon_{i}$ are, respectively output, a $J$ dimensional input vector (of which the $J$ th input is water), and error on plot $i$, and $\beta$ is a $J$ dimensional parameter vector. Having experimented with several functional forms, we chose the flexible, Translog function as a starting point. We found that the Cobb-Douglas production function nested by the Translog works best. ${ }^{10,11}$ Our production model is therefore

$$
\ln \left(y_{i}\right)=\sum_{j=1}^{J} \beta_{j} \ln \left(x_{i j}\right)+\sum_{t=1}^{T-1} \gamma_{t} d_{t}+\lambda d_{c}+u_{i}
$$

where $i$ indexes plots, $t$ indexes farmers, $\ln \left(x_{i 1}\right)=1$, for all $i, d_{t}=1$ if plot $i$ is cultivated by farmer $t$, and is zero otherwise; $d_{c}$ equals 1 if plot $i$ has a rattoon ${ }^{12}$ crop. The explanatory variables $x_{i j}$ are plot size, manure, fertilizer value, labor, tractor and oxen hours, and irrigation volume.

Table 3 presents the Cobb-Douglas production function estimates. All coefficients except fertilizers have the expected sign and all but fertilizers and manure are significant. We also experimented with alternative specifications: using soil quality both as instruments and independent variables. These turn out to be insignificant and do not greatly affect other estimated coefficients, suggesting that the estimated MPWs are fairly robust. Appendix A.1 details the

\footnotetext{
instruments such as soil quality variables and water price do not improve estimation. There is not enough variation in soil quality, while water prices are too weakly correlated with irrigation volumes. This last fact probably arises because under water rationing, the social contract allocates water efficiently across plots; so plots with different water prices can end up with similar irrigation volumes.

${ }^{10}$ We cannot reject the null that the higher order terms of the Translog are all zero. The $\mathrm{F}(1,281)$-statistic corresponding to this evaluates to 0.82 . The probability exceeding this value is 0.365 .

${ }^{11}$ We also considered the von Liebig production function that often works well in plant experiments (e.g. Paris and Knapp(1989)). However, the von Liebig implies a cost function linear in input prices. This is rejected by our data, so we did not estimate this form of production function.
} 
construction of $95 \%$ confidence bands around the MPW estimates; we will infer that water on a plot is rationed if the unit cost of water extraction is less than MVPW, and lies outside the confidence band.

The unit cost of water extraction from a tubewell does not depend on a charge for electricity, as that is a lump sum annual charge. But it depends on the number of pump breakdowns and the cost of repair per breakdown, since the number of such breakdowns is a function of the number of hours of tubewell operation. We model the number of breakdowns as a Poisson process, estimate the Poisson parameter from data on hours of operation and number of breakdowns for each pump. From this we derive tubewell-specific marginal cost of water extraction estimates, as detailed in Appendix A.2.

(2). Comparing MVPW on plots to unit costs of water extraction: Table 4 presents summary statistics of the derived plot level estimates of MPW, and the confidence bands. For the sample overall, the average MVPW (the MPW times the sugarcane price of Rs. 102 per quintal) is about Rupees 16.6 per additional bigha-inch of water (as noted earlier, 1 bigha-inch of water equals about 20.6 cubic meters). On the other hand, the estimated Poisson parameter for nonsubmersible and submersible pumpsets, respectively 0.002 and 0.0005 , yield estimated marginal costs of extraction that average to Rs.1.45 and Rs.0.3 per bigha-inch for the two pumpset types. Comparing the MVPW on each plot with the marginal cost of extraction from the tubewell that supplied water to it, we find that the former is significantly higher for every plot. Thus there is pervasive water rationing.

We also compare the MVPW for each plot with the tubewell-specific water price (Rs. 15 divided by the tubewell discharge per hour) for the plot. The mean MVPW is about 2.5 times

\footnotetext{
${ }^{12}$ Rattoon refers to a second year stalk from planted sugarcane, grown by leaving the roots and part of the stalk intact in the soil during the first harvest.
} 
greater than the mean water price of Rs. 6.53 per bigha-inch; in fact, the MVPW is significantly larger than the water price for 308 of the 326 plots.

Consider then a tubewell owner as a water selling farmer, as done in the earlier literature. In the sugarcane belt setting, this tubewell owner must take the water price $p$ determined at the village level as given, and so must decide how much water to sell, and how much to use on his own plot. If the MVPW on his own plot exceeds the water price, we should not observe any water sales: for it is then more profitable to first apply an incremental unit of water on his own plot than to sell it. But in the data, we observe substantial water sales, along with MVPW on tubewell-owners' plots being higher than the selling price of water ${ }^{13}$. We are led to conclude that, instead, a social contract operates and determines the water allocation: it is reasonable to assume that the water price and this allocation are jointly determined at the village level, as in the model of Section 4.

We now provide a simple model of this social contract. The model predicts that water allocation from a tubewell to the plots served by it is efficient. In the subsequent section, we juxtapose this prediction with what analyzing the data tells us about allocative efficiency in the village.

\section{A Simple Model of the Village Social Contract}

The model described below takes into account the following stylized facts. A uniform water price is agreed upon in the village at the beginning of the season. Most farmers own land in 2 or more fragments, do not have tubewells on all their plots/fragments, ${ }^{14}$ and are both buyers and sellers of water. Water is short due to power shortages. Tubewell owners sell water despite the

\footnotetext{
13 Plots with own tubewells are relatively less water-rationed. Table 4B shows that the mean MVPW for plots with own tubewell is Rupees 11.87, while for plots irrigated using purchased water it is Rupees 18.43.
} 
fact that the marginal value products of water on their own plots are significantly higher than the fixed water price that they receive from water sales. The allocation of water from a tubewell across plots served by it may not be significantly inefficient.

The model of a social contract that we will use is one of village-wide bargaining over water allocation across plots and water price. Water allocation affects outputs and profits on each plot, and thus the size of the total village 'pie'; while payments for water use result in a division of this pie across the farmers. In the village, who buys water from whom depends on plot locations, and this generally does not include reciprocal buyer-seller relationships between pairs of farmers. Rather, farmer A may be buying water from farmer B, who may be buying from farmer $\mathrm{C}$, and so on; so village-wide bargaining captures negotiations better than bargaining within small groups of farmers. We will apply the N-player Nash Bargaining model. ${ }^{15}$ Although this is a well-known model, we will explicitly map our village level features into it, for two reasons: (i) to provide predictions about water allocation that we should expect if the model is a reasonable approximation of village negotiations. (ii) The only transfers farmers make to each other is through payments for water use, at a single, common water price. It is useful to show how this affects the Pareto frontier and utility possibilities that farmers can attain.

Suppose there are $N$ farmers, and $N$ 'locations'. Farmer $j$ has 2 plots, in locations $j-1$ and $j$; so at each location $j$, there are 2 plots, owned by farmers $j$ and $j+1$ (modulo $N)^{16}$. The particular choice of number of plots and pattern of plot ownership is purely for simplicity. Farmer $j$ has a tubewell on his plot in location $j$ but not on his plot in location $j-1$, and his own

\footnotetext{
${ }^{14}$ As mentioned before, borewells and pumps are expensive, some plots are small relative to tubewell capacity, and water from the tubewell of a neighboring farmer may be available.

${ }^{15}$ Nash(1950), Lensberg(1988). Several non-cooperative bargaining models approximate the Nash Bargaining solution (e.g. Krishna and Serrano (1996)), so its use can be viewed as describing the outcome of an explicit bargaining process. The N-player version of Nash Bargaining ignores the possibility of the formation of coalitions of players, but in our setting, appears to capture village-wide agreement in a simple way.

${ }^{16}$ That is, $N+1$ refers to farmer 1 .
} 
tubewell is too distant to serve this latter plot. So for each $j$, irrigation on the 2 plots at location $j$ depends on farmer $j$ 's tubewell. The unit cost of water extraction is $c$ (for simplicity constant across tubewells). Crop output depends on water input alone (for simplicity): farmer j's outputs on his 2 plots are $A_{j j} f\left(w_{j j}\right)$ and $A_{j, j-1} f\left(w_{j, j-1}\right)$ respectively. (The first subscript refers to the farmer and the second to the location of the plot; for example, $w_{j, j-1}$ is the amount of irrigation on farmer $j$ 's plot in location $j-1 ; A_{j, j-1}$ is a plot-specific productivity for that plot). $f$ is twice continuously differentiable, strictly concave, with positive first derivative; and water is an essential input. Let the sugarcane output price be normalized to 1 , and let $p$ denote water price.

$$
\left(w_{j j}, w_{j+1, j}\right)_{j=1}^{N} \text {, or simply }\left(w_{j j}, w_{j+1, j}\right)_{j} \text {, will refer to a water allocation in the }
$$

village; the expression within parentheses gives the water supplied by tubewell $j$ to the plots of farmers $j$ and $j+1$ in location $j$. An agreement will be a tuple $\left(p,\left(w_{j j}, w_{j+1, j}\right)_{j}\right)$ consisting of a water price $p$ and a water allocation that all farmers agree upon. Every feasible agreement gives each farmer a specific level of profit; ('feasible' water prices and water allocations will be defined later).

(1). Water Allocation in the Absence of Rationing: We first show that in the absence of a (power shortage driven) water constraint, the water allocation in the Nash Bargaining solution would equate the marginal value product of water (MVPW) on each plot with the marginal cost of water extraction. The Nash Bargaining solution picks a point on the Pareto frontier of farmers' profits. To deduce the water allocation, it suffices to characterize the Pareto frontier. Let $S$ be the set of all feasible agreements. The Pareto frontier would be described by the solution to the 
following problem (which maximizes farmer 1's profits holding fixed the profits of the other farmers):

$\operatorname{Max}_{\left(p,\left(w_{j j}, w_{j+1, j}\right)_{j}\right) \in S} \quad A_{11} f\left(w_{11}\right)+A_{1 N} f\left(w_{1 N}\right)+p w_{21}-p w_{1 N}-c\left(w_{11}+w_{21}\right)$

s.t.

$A_{j j} f\left(w_{j j}\right)+A_{j, j-1} f\left(w_{j, j-1}\right)+p w_{j+1, j}-p w_{j, j-1}-c\left(w_{j j}+w_{j+1, j}\right)=\bar{\pi}_{j}$,

for all $j=2, \ldots, N$

Adding the constraints in Eq.(3), we get

$$
\sum_{j=2}^{N}\left[A_{j j} f\left(w_{j j}\right)+A_{j, j-1} f\left(w_{j, j-1}\right)-c\left(w_{j j}+w_{j+1, j}\right)-\bar{\pi}_{j}\right]+p w_{1 N}-p w_{21}=0
$$

Substituting this in the objective function of Eq.(3), the problem becomes

$$
\operatorname{Max}_{\left(w_{j j}, w_{j+1, j}\right)_{j}}\left[\sum_{j=1}^{N}\left(A_{j j} f\left(w_{j j}\right)+A_{j, j-1} f\left(w_{j, j-1}\right)-c\left(w_{j j}+w_{j+1, j}\right)-\bar{\pi}_{j}\right)\right]
$$

Rearrange Eq.(5) to have the entire water allocation from tubewell $j$ 'visible':

$$
\operatorname{Max}_{\left(w_{j j}, w_{j+1, j}\right)_{j}} \sum_{j=1}^{N}\left(A_{j j} f\left(w_{j j}\right)+A_{j+1, j} f\left(w_{j+1, j}\right)-c\left(w_{j j}+w_{j+1, j}\right)-\bar{\pi}_{j}\right)
$$

The first order conditions for an interior optimum are:

$$
A_{j j} f^{\prime}\left(w_{j j}\right)=c, A_{j+1, j} f^{\prime}\left(w_{j+1, j}\right)=c, \forall j .
$$

That is, the MVPW on each plot equals the unit cost of water extraction; every point on the Pareto frontier of farmers' profits corresponds to agreements with the same, efficient water allocation described by Eq.(7). But the data show that MVPW greatly exceeds the unit cost of extraction on each plot (Section 3.1(2)); so, an appropriate model of a social contract in the village must take into account the fact that limited power supply rations the amount of water available, as it does in the modeling that follows. 


\section{(2). The Social Contract Under Water Rationing}

Suppose that the discharge from tubewell $j$ is constrained to be at most $\bar{w}_{j}, j=1, \ldots, N$. If $w_{j j}, w_{j+1, j}$, the solutions to Eq.(7) above, add up to a number greater than $\bar{w}_{j}$, plots will be water-rationed; this is the case suggested by the data. Purely to simplify some expressions (those for the disagreement point in Nash Bargaining), we make a stronger assumption.

(Assumption $R$ ): $A_{j j} f^{\prime}\left(\bar{w}_{j}\right)>c, \forall j=1, \ldots, N$. That is, even if the entire amount discharged by tubewell $j$ is applied to farmer $j$ 's plot at that location, the MVPW on the plot exceeds the unit cost of water extraction. In the absence of an agreement of water price and water allocation, farmer $j$ therefore gets a 'disagreement' profit $d_{j}=A_{j j} f\left(\bar{w}_{j}\right)-c \bar{w}_{j}$ (since without getting any water on his plot in location $j-1$, its output is 0 ).

The Pareto frontier of the set of profit possibilities is now characterized by:

$\operatorname{Max}_{\left(p,\left(w_{j j}, w_{j+1, j}\right)_{j}\right) \in S} A_{11} f\left(w_{11}\right)+A_{1 N} f\left(w_{1 N}\right)+p w_{21}-p w_{1 N}-c \bar{w}_{1}$

s.t.

$A_{j j} f\left(w_{j j}\right)+A_{j, j-1} f\left(w_{j, j-1}\right)+p w_{j+1, j}-p w_{j, j-1}-c \bar{w}_{j}=\bar{\pi}_{j}, \forall j=2, \ldots, N$

and $\quad w_{j j}+w_{j+1, j}=\bar{w}_{j}, \forall j=1, \ldots, N$.

Here, the set $S$ of feasible agreements consists of tuples of non-negative water price and water allocations that do not exceed the water available from each tubewell, and that result in each farmer's profit being at least as large as his disagreement profit. It follows from Assumption $R$ that all available water is utilized; so the constraints in Eq.(9) hold with equality. Carrying out the same operations that helped rewrite Eq.(3) in the form of Eq.(6), the above maximization problem can be posed as: 
$\operatorname{Max}_{\left(w_{j j}, w_{j+1, j}\right)_{j}} \sum_{j=1}^{N}\left(A_{j j} f\left(w_{j j}\right)+A_{j+1, j} f\left(w_{j+1, j}\right)-c \bar{w}_{j}-\bar{\pi}_{j}\right)$

s.t. $\quad w_{j j}+w_{j+1, j}=\bar{w}_{j}, \forall j=1, \ldots, N$

The first order conditions imply

$A_{j j} f^{\prime}\left(w_{j j}\right)=A_{j+1, j} f^{\prime}\left(w_{j+1, j}\right), \forall j=1, \ldots, N$.

That is, water in each location $j$ is allocated to equate MVPW on the plots in that location. Let this efficient water allocation be denoted $\left(w_{j j}^{*}, w_{j+1, j}^{*}\right)_{j}$. Every point on the Pareto frontier of farmers' profits therefore arises from this common, efficient water allocation (efficient subject to the water constraints). We now describe the Pareto frontier fully, followed by the Nash Bargaining solution for the problem.

Farmer $j$ 's profit at the efficient allocation is equal to

$$
\begin{aligned}
\pi_{j} & =A_{j j} f\left(w_{j j}^{*}\right)+A_{j, j-1} f\left(w_{j, j-1}^{*}\right)-c \bar{w}_{j}+p\left(w_{j+1, j}^{*}-w_{j, j-1}^{*}\right) \\
& =\pi_{j}^{0}+p s_{j}
\end{aligned}
$$

where $s_{j}$ equals his net water sales at the efficient water allocation, and $\pi_{j}^{0}$ is his profit at this allocation, if the water price equals zero. The Nash Bargaining solution is a tuple of farmers' profits $\left(\pi_{1}^{n b}, \ldots, \pi_{N}^{n b}\right)$ that solves

$$
\operatorname{Max}_{\left(\pi_{1}, \ldots, \pi_{N}\right) \in \Theta} \Pi_{j=1}^{N}\left(\pi_{j}-d_{j}\right)
$$

where $\Theta$ is the set of all profit tuples $\left(\pi_{1}, \ldots, \pi_{N}\right)$ that lie on the Pareto frontier and satisfy $\pi_{j} \geq d_{j}, \forall j$. In Nash Bargaining problems which divide a 'surplus' (such as here), and where the players can make arbitrary monetary transfers (that add up to 0 ) to each other, the Pareto frontier is an $(N-1)$-dimensional hyperplane in the space $\mathfrak{R}^{N}$ of the N-players' payoffs. But in 
our setting this is not the case, because the only transfers farmers can make is through payment of the water price; and the efficient water allocation creates sets of net water buyers and sellers. This restricts $\Theta$ to being a line segment in $\mathfrak{R}^{N}$, with direction determined by the identities of net water sellers versus buyers, as derived below.

Let $N B=\left\{j \mid s_{j}<0\right\}, N S=\left\{j \mid s_{j} \geq 0\right\}$ be the subsets of farmers that are respectively net buyers and net sellers of water, at the efficient water allocation. For a water price to be feasible, it must be non-negative, and satisfy $\quad \pi_{j}^{0}+p s_{j}-d_{j} \geq 0, \forall j$. For feasible water prices to exist, it must be that for all net water buyers, $\pi_{j}^{0}-d_{j}>0$. We have that, at the efficient water allocation, the set of feasible water prices is the closed interval $[m, M]$, where ${ }^{17}$

$$
M=\min \left\{-\left(\pi_{j}^{0}-d_{j}\right) / s_{j} \mid j \in N B\right\}, m=\max \left\{0, \max \left\{-\left(\pi_{j}^{0}-d_{j}\right) / s_{j} \mid j \in N S\right\}\right\}
$$

So a water price $p>M$ implies that some net water buyer (at the efficient water allocation) is better off at his disagreement payoff than on agreeing to this price. Similarly, $p<m$ means that some net water seller (at the efficient water allocation) is better off at his disagreement payoff than on an agreement at this price. Therefore, we have

$\Theta=\left\{\left(\pi_{1}, \ldots, \pi_{N}\right)=\left(\pi_{1}^{0}, \ldots, \pi_{N}^{0}\right)+p\left(s_{1}, \ldots, s_{N}\right) \mid p \in[m, M]\right\}$

This is a line segment through the point $\left(\pi_{1}^{0}, \ldots, \pi_{N}^{0}\right)$, in the direction of $\left(s_{1}, \ldots, s_{N}\right)$, the net water trades of the farmers. The Nash Bargaining objective function (Eq.(13)) is continuous on the compact set $\Theta$, so a maximum (a Nash Bargaining solution) exists; it is unique because the objective is strictly quasiconcave. Thus, there is agreement on a unique water price $p \in[m, M]$.

${ }^{17}$ We assume $m<M$ : this always holds if $\pi_{j}^{0}-d_{j}>0, \forall j$. 
Since $\Theta$ lies entirely in the interior of the positive orthant, it is possible that the solution is at one of its 2 endpoints, corresponding to $p$ equaling $m$ or $M$.

The model of the social contract has the following 3 implications, among others. First, the Nash Bargaining solution for the case of water rationing predicts that each tubewell allocates water efficiently across the plots it serves. In Section 5 below, we therefore first explore how closely this prediction is borne out by our analysis of the village data. Second, the Nash Bargaining solution restricts the water price $p$ to an interval $[m, M]$ that can in principle be determined, or at least estimated; however, this requires us to have plot and water allocation data for the entire village (not just a sample) ${ }^{18}$. Note also that $p$ is not necessarily higher or lower than the unit cost of water extraction, bearing out our criticism of using price-cost margins to infer water allocative efficiency, as done in the literature. Finally, in the absence of a water constraint, the Nash Bargaining solution predicts that water is allocated to each plot up to the point where its MVPW equals its marginal cost of extraction. In our Policy exercise in Section 5, we explore the effects of relaxing the power and water shortage, using this latter water allocation.

\section{Implications of the Social Contract}

5.1 Allocative Efficiency: To begin assessing whether or not water allocation across plots is efficient, we compare the MPWs across plots. These MPW estimates are significantly different (in terms of our constructed confidence bands) from each other, suggesting, prima facie, allocative inefficiency. But in fact, the inefficiency is quite limited, particularly when we compare MPWs across plots serviced by the same tubewell (as suggested by the model). An analysis of variance of the MPWs shows that less than half the variation of the total sum of

\footnotetext{
${ }^{18}$ Given output and input prices, water constraints, and the estimated production function on all plots, we can of course compute the water price at the Nash Bargaining solution, for comparison with the water price in the data. However, the two may differ simply because our model assumes symmetric bargaining power across farmers; so such a comparison is not meaningful.
} 
squares (9.6 of 20.6) is attributable to within-group variation (i.e. variation of MPWs across plots served by the same tubewell). The variation of MPWs on plots serviced by the same tubewell results in lower total output aggregated over those plots, relative to output corresponding to the efficient water allocation that equalizes MPWs across these plots.

We estimate the extent of these output (and profit) losses by posing the following question. What would the outputs from the sample plots be if the total observed water from each tubewell in the sample is allocated efficiently across the plots that are serviced by that tubewell? Suppose for every plot $i$ in the data set, the choice $\left(x_{i j}\right)$ of inputs other than irrigation has been made as in the data. Suppose the constant marginal cost of water extraction from tubewell $t$ is $C_{t}$, and let $U(t)$ be the set of all plots in the sample that are serviced by tubewell $t$. Let $\bar{w}_{t}$ be the total volume of water discharged from tubewell $t$ : this is given from the data. An efficient allocation $\left(\hat{x}_{i J}\right)_{i \in U(t)}$ of water would be a vector that maximizes

$\sum_{i \in U(t)}\left[p_{s} f\left(\left(x_{i j}\right), \hat{x}_{i J}, \beta\right)-c_{t} \hat{x}_{i J}\right]$, subject to the constraints

$\sum_{i \in U(t)} \hat{x}_{i J} \leq \bar{w}_{t}$, and for all $i \in U(t), \hat{x}_{i J} \geq 0$

The constraint $\sum_{i \in U(t)} \hat{x}_{i J} \leq \bar{w}_{t}$ captures the water shortage implied by limited electricity supply. Note that at the solution, MVPW will be equated across plots. We solve this problem, evaluated at the estimated parameter vector $\hat{\beta}$ and estimated production function and unit cost of water extraction, $f$, and $\hat{c}_{t}$ respectively, for each tubewell in the data set. Then we compare the total simulated output with the total output in the sample. 
Note again that the mapping from tubewells to user plots stays the same as in the sample; ${ }^{19}$ given that water is transported through unlined water channels, this mapping is largely determined by proximity of plots to particular tubewells. ${ }^{20}$

As indicated in Table 5, redistributing water results in an average gain of less than 0.2 quintals per bigha, with the highest gain of 1 quintal per bigha (a gain of about 2\%; in value, Rs.102 per bigha) on plots which purchase water. We infer that the social contract appears to work extremely well, allocating water efficiently across plots, minimizing losses in overall yields in the face of water rationing.

It may be worthwhile reiterating that thinking about tubewell owners as water selling firms trying to maximize profits (as done in much of the literature) does not fit well our setting in North India. Consider the following little thought exercise: suppose the tubewell owners in the data take the village level water price of Rupees 15 per hour as given; suppose also that water from each tubewell is constrained to be equal to the amount recorded in the data. Given these, suppose that starting from the sample water allocation, the tubewell owners reallocate water across plots serviced by their tubewells, in order to maximize profits from individual tubewell water sales. We ran this as a simulation and found, naturally, that given MVPWs on their own plots are greater than the water price in the sample, there is reallocation of water towards the tubewell owners' plots, and away from water buying plots. Simulated output on plots with tubewells increases by 0.7 quintals per bigha on average, but average yields on plots that buy water drop from 53.7 to 16.30 quintals per bigha! This poor allocation results in overall yield in the village declining from 57.51 to 48.14 quintals per bigha. This exercise reinforces the fact that

\footnotetext{
${ }^{19}$ So each plot serviced by the same tubewell faces the same marginal cost for water. Given water rationing, choosing a water allocation to maximize joint profits for these plots is the same as maximizing joint output.
} 
it is better to think about water allocation, at least in this large belt in North India, as arising out of a village-level social contract.

\subsection{Impact of Alternative Power Policy}

In earlier literature (and possibly different settings) in South Asia, a case has been made for engineering efficiency (or equity) enhancing redistributions in water allocation (e.g. Jacoby, Murgai, Rahman (2004)); in our setting, such policy is unnecessary. Instead, relaxing the water constraint will increase efficiency, as is clear from the model ${ }^{21}$. But this will require improving power supply ${ }^{22}$. The present system of an annual payment for a pump based on horsepower, however, does not give the power provider incentive to provide incremental power; ${ }^{23}$ a system of unit pricing of electricity at remunerative levels can positively alter incentives. Improving power supply without unit pricing of electricity, even if this can be implemented, leads to a marginal cost of extracting water far below its social cost, and can lead to great overuse. Keeping these points in mind, we ask:

What would be the effect of unit pricing of power (at different levels), and reliable power supply, on yields, profits, irrigation volumes and power revenue?

We are interested in finding out whether there are unit electricity prices that fetch a profit for the power provider (making it incentive compatible to provide reliable power), and yet are acceptable to farmers because the improved power supply adds to their crop yields and profits as well; and further, if at such unit power prices, irrigation volumes do not indicate much overuse relative to sample volumes.

\footnotetext{
${ }^{20}$ This paper does not address questions of changes in water transport technology (such as a system of pipes); therefore, it is reasonable to retain the tubewell-user plot mapping as is. We found, though, that even allowing for unrestricted redistribution of water across all plots increases average yield by less than 0.5 quintals per bigha.

${ }^{21}$ Inadequate water arising out of power shortages also leads to improperly timed irrigations, and harms plant growth. This effect is not modeled or measured in this paper.

${ }_{22}$ Changes in the power policy regime have been advocated by several authors, on a number of counts.

${ }^{23}$ It is unreasonable to believe that reliable and adequate power can be provided by contract, in the present context.
} 
Modeling the Simulation: Each unit power price is translated into a unit cost of water extraction, the exact conversion depending on pump horsepower. Eq. (7) of Section 4 says that for water allocations determined by Nash bargaining, the absence of a water constraint will lead to MVPWs being equated to the unit cost of extraction. Using this and the estimated production function and other input prices, we simulate optimal input choices for buyers and sellers of water, water allocation, and village averages for yield, profits, irrigation volumes and power revenue (see Appendix A.3 for details).

Results of the Simulation. We vary the unit power price from Rs.1.80 (comparable to some estimates of average power generation costs in India; power transmission and distribution costs are additional), in increments of Rs. 0.1, to Rs.4.50 per kilowatt-hour (kWhr). The latter roughly corresponds to commercial (industrial) rates in several parts of the country. ${ }^{24}$

An extract of the results is in Table 6. Sample values for yield, profit per bigha, irrigation volume per bigha and power revenue per bigha are respectively 58.22 quintals, Rs.2490 (profit per bigha would be Rs.2220, if pump horsepower was not underreported), 30 bigha-inches and Rs. $270 .^{25}$ These are recorded in Table 6 as the "sample" scenario; for which the unit power price is zero (and there is a lump sum monthly charge of Rs.70 per reported horsepower). At a power price of Rs.4.50 per kW hour (close to rates charged to industry), irrigation volume is 30.23 bigha-inches, yield is about 61 quintals, profits are Rs.2051, and revenue to the power provider is Rs.852. As the power price is lowered gradually to Rs.1.80, irrigation volume increases to about 34.66 bigha-inches, yield increases slowly, to reach about 63.61 quintals, power revenue per bigha decreases to Rs.386.21.

\footnotetext{
${ }^{24}$ Commercial rates also include a lump sum charge per kilowatt of sanctioned load.

${ }^{25}$ Profit is calculated as revenue minus wage cost, rental costs of tractors and oxen, fertilizer cost and water cost; and cost of power for tubewell owners. We do not subtract imputed land rent. Incidentally, in this area, there is very
} 
Note first that at 30.23 bigha-inches of irrigation, the yield of 61 quintals is 2.88 quintals above the sample yield of 58.22 quintals, for which irrigation is only slightly lower at 30.02 bigha-inches. Part of this increase is attributable to higher input use in the simulation, relative to the sample; with positive cross-partial derivatives in the production function, this increases yield at the same level of water-use as in the sample. ${ }^{26}$ Yield increments thereafter are slow and diminish at higher irrigation levels.

Table 6 shows that for power prices up to Rs.2.50 per kWhr, farmers' profits and the power supplier's revenues are both greater than their sample values; the significantly higher simulated yields can therefore pay for electricity prices that cover the cost of power generation. In the present setup of lump sum power payments based on pump horsepower, there is widespread underreporting of horsepower. Accurate assessments of pump horsepower would decrease sample profits and increase sample power revenue by Rs.270 per bigha each. Under such an alternative baseline scenario, Table 6 suggests that power prices between Rs.2.70 and Rs.3.60 per kWhr are consistent with both profits and power revenue being larger than their baseline values.

The simulation therefore implies that even in the presence of a social contract that results in a close-to efficient allocation of scarce water, a switch to remunerative power pricing is feasible, acceptable to both farmers and power providers, and will result in a substantial increase in yields. But water use is heavier than in the sample at power price levels that are politically acceptable at present. ${ }^{27}$

little land given out on rent. The wage cost includes an imputed wage for family labor, which can be quite important in several activities.

${ }^{26}$ The lower input use in the sample is likely because power and water were in shorter supply in the crucial summer months than later on. This led to lower application of fertilizers (which require water) and correspondingly of labor input. Our formal analysis, of course, lacks this timing aspect of farm activity.

${ }^{27}$ These simulations provide a lower bound on yield gains. Unreported simulations that set insignificant parameter estimates of the production to zero suggest that yield gains could be higher. Moreover, the reported simulation takes 


\section{Discussion and Conclusions}

The literature on water economics has many examples of water supply systems in the world pricing water at average rather than marginal cost, resulting in inefficiency (Schoengold and Zilberman(2005)). In this paper, however, we discover a village-level system with rigid trading prices having no bearing on marginal product, and yet a close to efficient water allocation governed by a social contract. This is more striking because the literature has often inferred the existence of local monopoly and inefficiency in similar settings of unlined water channels and reduced radii of operations of tubewells (Jacoby, Murgai, Rahman (2004)).

Features such as land fragmentation and ownership of multiple plots that drive the usefulness of the social contract are widespread in India; it is a reasonable conjecture that efficient spatial water allocation, or something close to that, occurs elsewhere as well. The causes of inefficiency in groundwater irrigation lie elsewhere, and the policy debate should shift focus to address those (rather than worry about water allocations within villages).

First, irregular and inadequate supply of power reduces crop yields by adversely affecting both the quantum and the timing of irrigations. Our simulations show that reliable power supply can improve yields by up to $10 \% ;^{28}$ the additional profits can more than pay for pricing power at unit cost. However implementing a change in the power regime is a challenge. The system of public ownership and political capture of power supply to agriculture needs to be replaced; but a discussion of the alternative combinations of private/public ownership, competition, regulation and realignment of expectations necessary to replace it is beyond the scope of this paper.

acreage as given in the sample, but easier water availability would expand that. In addition, proper timing of irrigations is crucial for plant growth (Evenson, Pray and Rosegrant (1999)); inadequate power compromises this as well. But our aggregative analysis cannot quantify the amount of damage that is attributable to lack of timely irrigations. 
Switching from a non-remunerative power price-poor power supply regime to a higher pricereliable supply one can be viewed as a move from a low-level to a high-level equilibrium (Spiller and Savedoff (1999)), and as is generally the case, moving from one to the other may involve institutional changes.

Moving to a new power pricing regime has the added benefit of addressing the second, intertemporal, inefficiency embodied in over-extraction of groundwater. Traditional rights in India allow a land-owning farmer unlimited access to the groundwater beneath his land. The negative externality ${ }^{29}$ on other aquifer users' future pumping costs and foregone profits is likely exacerbated by the small size of landholdings, relative to aquifer area. While empirical study of this externality is beyond the scope of this paper, a companion paper suggests that a markup applied on the economic cost of power can tax the pumping of groundwater and align a farmer's static private marginal cost of water extraction to its social cost. The socially optimal markup (in the steady state of a simple dynamic model) turns out to be about $15 \%$ of the unit cost of electricity. Reforming the power sector can thus achieve the twin objectives of reliable power for greater agricultural productivity and sustainable groundwater use.

\section{REFERENCES}

Binmore, K.G., A. Rubinstein and A. Wolinsky (1986): "The Nash Bargaining Solution in Economic Modelling”, Rand Journal of Economics, vol.17, 176-188.

Dhawan, B.D. (1995): “Groundwater Depletion, Land Degradation and Irrigated Agriculture in India”, Commonwealth Publishers.

Dubash, Navroz K. (2002): "Tubewell Capitalism: Groundwater Development and Agrarian Change in Gujarat”, Oxford University Press, New Delhi.

\footnotetext{
${ }^{28}$ This could be an underestimate as our estimation may not adequately capture the effect of irrigation timing, which can be improved through reliable power supply.

${ }^{29}$ See Shah, Zilberman and Chakravorty (1993) for a discussion of first and second-best solutions to the externality problem related to groundwater use.
} 
Evenson, R., C. Pray and M. Rosegrant (1999): “Agricultural Research and Productivity Growth in India”, IFPRI Research Report \# 109, Washington, D.C.

Foster, Andrew and Mark Rosenzweig (2005): "Inequality and the Sustainability of Agricultural Productivity Growth: Groundwater and the Green Revolution in Rural India” mimeo.

Griliches, Z. and J. Mairesse (1998): “Production Functions: The Search for Identification”, in Econometrica and Economic Theory in the Twentieth Century: The Ragnar Frisch Centennial Symposium, pp169-203. Cambridge University Press.

Jacoby, Hanan G., Rinku Murgai and Saeed Ur Rehman (2004): "Monopoly Power and Distribution in Fragmented Markets: The Case of Groundwater", The Review of Economic Studies, vol.71, 783-808.

Krishna, V. and R. Serrano (1996): “Multilateral Bargaining”, Review of Economic Studies, vol. 63, 61-80.

Lensberg, T. (1988): “Stability and the Nash Solution”, Journal of Economic Theory, vol. 45, 330-341.

Levinsohn, J. and A. Petrin (2003): "Estimating Production Functions using Inputs to Control for Unobservables”, Review of Economic Studies, vol.70, 317-342.

Marschak, J. and W. Andrews (1944): "Random Simultaneous Equations and the Theory of Production." Econometrica, vol.12, 143-205.

Meinzen-Dick, R (1996): “Groundwater Markets in Pakistan: Participation and Productivity”, International Food Policy Research Institute Research Report, 105.

Meinzen-Dick, R. (2000): "Public, Private and Shared Water: Groundwater Markets and Access in Pakistan”, in Negotiating Water Rights (ed) Bryan Randolph Bruns and Ruth Meinzen-Dick. Intermediate Technology Publications, UK.

Nash, J. (1950): “The Bargaining Problem”, Econometrica, vol. 18, 155-162.

Olley, S. and A. Pakes (1996): "The Dynamics of Productivity in the Telecommunications Industry”, Econometrica, vol. 64, pp169-203.

Palmer-Jones, R. (1994): "Groundwater Markets in South Asia: A Discussion of Theory and Evidence”, in Selling Water: Conceptual and Policy Debates over Groundwater Markets in India. VIKSAT, Ahmedabad, India.

Pant, N. (2004): “Trends in Groundwater Irrigation in Eastern and Western UP”, Economic and Political Weekly, July 31. 
Paris, Q. and K. Knapp (1989): “Estimation of von Liebig Response Functions”, American Journal of Agricultural Economics 71, 178-86.

Ross, S. (1997): “Introduction to Probability Models”, Chapter 5, Academic Press.

Schoengold, K., and D. Zilberman (2005): "The Economics of Water, Irrigation and Development”, forthcoming in R. Evenson (ed.), Handbook of Agricultural Economics, Vol.3 (Elsevier).

Sengupta, Nirmal: "Negotiation with an Under-informed Bureaucracy: Water Rights on System tanks in Bihar" in Bryan Randolph Bruns and Ruth S. Meinzen-Dick, editors, Negotiating Water Rights (Intermediate Technology Publications, 2000).

Shah, Tushaar (1993): “Groundwater Markets and Irrigation Development: Political Economy and Practical Policy", Oxford University Press, New Delhi.

Shah, F., D. Zilberman and U. Chakravorty (1993): "Water Rights Doctrines and Technology Adoption", in K. Hoff, A. Braverman and J. Stiglitz (eds.), The Economics of Rural Organization: Theory, Practice and Policy. Oxford University Press.

Somanathan, E., and R. Ravindranath (2006): "Measuring the Marginal Value of Water and Elasticity of Demand for Water in Agriculture”, Economic and Political Weekly, June 30.

Spiller, P.T. and W.D. Savedoff (1999): Government opportunism and the provision of water. In Spiller and Savedoff (eds.), Spilled water: institutional water. Institutional Commitment in the Provision of Water Services. Inter-American Development Bank. Washington, USA. 


\section{APPENDIX A. TECHNICAL DETAILS}

\section{A.1. Confidence Intervals for Marginal Product of Water}

In multiplicative form, the fitted value of Cobb-Douglas output on plot $i$ evaluates to

$f\left(x_{i}, \hat{\beta}\right)=e^{\left(\hat{\beta}_{1}+\sum \hat{\gamma}_{t} d_{t}+\hat{\lambda} d_{c}\right)} x_{i 2}^{\hat{\beta}_{2} \ldots x_{i J} \hat{\beta}_{J}}$. Correspondingly, the estimate of marginal product of water (MPW) on the plot equals

$$
f_{J}\left(x_{i}, \hat{\beta}\right)=e^{\left(\hat{\beta}_{1}+\sum \hat{\gamma}_{t} d_{t}+\hat{\lambda} d_{c}\right)} \hat{\beta}_{J} x_{i 2}^{\hat{\beta}_{2}} \ldots x_{i J}^{\hat{\beta}_{J}-1}
$$

(where $f_{J}$ is the partial derivative of $f$ with respect to $x_{J}$ (the volume of water)). There is water rationing if the marginal value product is significantly greater than the water cost. To assess this, we construct for each plot $i$ a 95\% confidence band $\left(a_{i}, b_{i}\right)$ around the MPW, using asymptotic theory.

Since $\hat{\beta}$ is consistent, for a large enough sample we can take a first-order Taylor approximation of the marginal product:

$$
f_{J}\left(x_{i}, \hat{\beta}\right)-f_{J}\left(x_{i}, \beta\right) \approx D_{\beta} f_{J}\left(x_{i}, \beta\right)^{T}(\hat{\beta}-\beta)
$$

where $D_{\beta} f_{J}\left(x_{i}, \beta\right)^{T}$ is the transpose of the gradient of the function $f_{J}$ (with respect to the parameter vector $\beta$ ), evaluated at $\left(x_{i}, \beta\right)$. Let $V=\operatorname{Cov}(\hat{\beta}) / n$, or a consistent estimator of it. If $\hat{\beta}$ is asymptotically normal, we have

$$
\sqrt{n}(\hat{\beta}-\beta) \stackrel{d}{\longrightarrow} N(0, V)
$$

From Eq.(A.1.1) and (A.1.2) we get

$$
\sqrt{n}\left(f_{J}\left(x_{i}, \hat{\beta}\right)-f_{J}\left(x_{i}, \beta\right)\right) \stackrel{d}{\longrightarrow} N\left(0, D_{\beta} f_{J}\left(x_{i}, \beta\right)^{T} V D_{\beta} f_{J}\left(x_{i}, \beta\right)\right)
$$

Or, in simpler notation,

$$
\sqrt{n}\left(\hat{m}_{w_{i}}-m_{w_{i}}\right) \stackrel{d}{\longrightarrow} N\left(0, \sigma_{w_{i}}^{2}\right)
$$

Replace $\beta$ with $\hat{\beta}$ on the RHS in Eq.(A.2.3), and call the resulting variance $\hat{\sigma}_{w_{i}}^{2}$. Using this and Eq.(A.1.4), we have

$$
\frac{\left(\hat{m}_{w_{i}}-m_{w_{i}}\right)}{\hat{\sigma}_{w_{i}} / \sqrt{n}} \stackrel{d}{\longrightarrow} N(0,1)
$$

From this we get the 95\% confidence interval

$$
\operatorname{Pr}\left(m_{w_{i}} \in\left(\hat{m}_{w_{i}}-\frac{1.96 \hat{\sigma}_{w_{i}}}{\sqrt{n}}, \hat{m}_{w_{i}}+\frac{1.96 \hat{\sigma}_{w_{i}}}{\sqrt{n}}\right)\right)=0.95
$$




\section{A.2. Estimating Marginal Cost of Water Extraction from a Tubewell}

Farmers pay a lump sum annual electricity charge for running a tubewell. So the marginal cost of water extraction includes only those maintenance costs that depend on water output. Maintenance costs are essentially costs of repairing the pump set in the event of a breakdown. While the frequency of breakdowns is high due to power surges, what is germane here is that the number of breakdowns may depend on the number of hours that the tubewell operates. It also depends on whether the machine is a submersible (fewer breakdowns) or a non-submersible. We assume that the number of breakdowns follows a Poisson Process (see Ross (1997)) with parameters $\mu_{1}, \mu_{2}$ for submersibles and nonsubmersibles respectively. Let $J_{1}, J_{2}$ be the sets of submersibles and non-submersibles respectively. So, for submersible tubewell $j$, the probability that the number of breakdowns $N$ equals $n_{j}$ if it runs for time $h_{j}$

$\operatorname{Pr}\left(N\left(h_{j}\right)-N(0)=n_{j}\right)=e^{-\mu_{1} h_{j}} \frac{\left(\mu_{1} h_{j}\right)^{n_{j}}}{n_{j} !}$

Using Eq.(A.2.1) and data on total number of breakdowns and number of running hours for each submersible tubewell, we set up a likelihood function and get an estimate $\hat{\mu}_{1}$ for the Poisson parameter.

Since the likelihood of the submersible sample $\left(h_{j}, n_{j}\right)_{j \in J_{1}}$ is

$$
e^{-\mu_{1} \sum_{j \in J_{1}} h_{j}} . \mu_{1}^{\sum_{j \in J_{1}} n_{j}} . \Pi_{j \in J_{1}}\left(\frac{h_{j}{ }^{n_{j}}}{n_{j} !}\right)
$$

the first order condition yields the maximum likelihood estimate

$\hat{\mu}_{1}=\frac{\sum_{j \in J_{1}} n_{j}}{\sum_{j \in J_{1}} h_{j}}$

which is just the total (or average) number of submersible breakdowns in the data divided by the total (or average) number of hours that submersibles in the data ran for. A similar exercise yields the Poisson parameter estimate for non-submersibles.

Suppose that it takes time $t_{j}$ to extract 1 unit (bigha-inch) of water using submersible tubewell $j$.

Then, the expected number of breakdowns in this time, $E\left(N\left(t_{j}\right)\right)=\hat{\mu}_{1} t_{j}$

Our estimated marginal cost of water extraction from this tubewell is the above number times the average cost of repair. 


\section{A.3. Modeling the Policy Simulation (Section 5.2)}

Suppose farmer $s$ owns plot $s$, and the tubewell $t$ on it, and suppose that $B(t)$ is the set of plots that buy water from this tubewell. With reliable power supply, the high density of tubewells, and the present aquifer depth of more than 100 feet, there is no water constraint. Suppose that farmer s's optimal input choices are $\left(\left(\hat{x}_{s j}\right), \hat{x}_{s J}\right)$, and those for the water buyers are $\left(\left(\hat{x}_{i j}\right), \hat{x}_{i J}\right)_{i \in B(t)}$ (the $J$ th input being water). The social contract in this 'no water constraint' case, discussed in Eq.(8-10) in the text, suggests that water would be allocated efficiently, which now translates to equating MVPW on any plot with the unit cost of water extraction $c_{t}$ from tubewell $t$. With price $p_{s}$ for sugarcane, and $q_{j}, j \neq J$ for other inputs, we can solve for the optimal input choices of farmer $s$ as follows:

$$
\left(\left(\hat{x}_{s j}\right), \hat{x}_{s J}\right) \in \arg \max \left[p_{s} f\left(\left(x_{s j}\right), x_{s J}, \beta\right)-\sum_{j} q_{j} x_{s j}-c_{t} x_{s J}\right]
$$

And similarly for all plots $i \in B(t)$,

$$
\left(\left(\hat{x}_{i j}\right), \hat{x}_{i J}\right) \in \arg \max \left[p_{s} f\left(\left(x_{i j}\right), x_{i J}, \beta\right)-\sum_{j} q_{j} x_{i j}-c_{t} x_{i J}\right]
$$

That is, the optimization problems of the different plots can be solved separately, because there is no common water constraint like in Simulation 1. From the solutions to plot level optimization problems, we derive per bigha averages for ouput, profit, irrigation volume, and power revenue, and compare them with the baseline numbers observed in the data.

Basic Assumptions: In the data set, tubewell pump set owners are charged Rupees 70 per horsepower per month. Most farmers misreport pumps to have 10 horsepower, so annual charges are about Rupees 8700 (8400 + other minor charges). But in actual fact, almost all pumps run on 20 horsepower. ${ }^{30}$ We base our simulations on this fact. Thus a unit power price of y rupees per $\mathrm{kW}$ hour translates to approximately $15 y$ rupees per hour, for a 20 horsepower pump. ${ }^{31}$ Dividing this by the discharge from the tubewell, and adding to that the estimated marginal cost of water extraction from this tubewell in the absence of unit pricing of electricity (as in the data), ${ }^{32}$ we get a simulated unit cost of extracting 1 bigha-inch of water from it. With the extraction costs from each tubewell in place, and other input and output prices as given in the sample, we endow each plot with the estimated production technology, and allow each plot in the sample to choose labor, tractor and oxen hours, and irrigation volumes, in order to maximize profits as described by Eqs.(A.3.1) and (A.3.2). ${ }^{33}$ Note that we hold fixed the mapping of tubewell to user plot; this determines specific water costs for each plot.

\footnotetext{
${ }^{30}$ Given the shortage of electricity to pump water, farmers compensate by having more tubewells and horsepower than would otherwise be necessary, in order to pump up water as quickly as possible.

${ }^{31}$ Since 1 horsepower is approximately $3 / 4$ of a kilowatt. Unless the pump is simply idling, a running $20 \mathrm{HP}$ pump consumes close to that.

${ }^{32}$ As reported earlier, the estimated marginal costs of extraction for non-submersibles and submersibles pumpsets average to, respectively, Rs. 1.45 and Rs. 0.3 per bigha-inch of water.

${ }^{33}$ Acreage and the variables with insignificant estimates (Table 3) are not optimized over.
} 


\section{TABLES}

Table 1. Summary Statistics on Water Use and Yields

1.1. Characteristics of Tubewells with Submersible and Non-submersible Pumpsets.

\begin{tabular}{|l|c|c|}
\hline & $\begin{array}{c}\text { Submersible } \\
\text { pumpsets }\end{array}$ & $\begin{array}{c}\text { Non-submersible } \\
\text { pumpsets }\end{array}$ \\
\hline Average electricity costs (Rs.) per year & 9665 & 9012 \\
\hline Average number of times repairs were effected & 1.5 & 3.2 \\
\hline Average maintenance costs (Rs.) per year & 3356 & 6151 \\
\hline Average time taken to irrigate one bigha (minutes) & 90 & 120 \\
\hline
\end{tabular}

\subsection{Irrigation Details, by Category of Plot}

\begin{tabular}{|l|c|c|}
\hline & $\begin{array}{c}\text { Plots with Own } \\
\text { Tubewell }\end{array}$ & $\begin{array}{c}\text { Plots using } \\
\text { purchased water }\end{array}$ \\
\hline Number of plots & 240 & 86 \\
\hline Mean number of irrigations & 10.2 & 8.0 \\
\hline $\begin{array}{l}\text { \% plots receiving 5 irrigations before 31 July } \\
\text { (start of monsoon) }\end{array}$ & 67 & 37 \\
\hline
\end{tabular}

\subsection{Yields of Sugarcane, by Category of Plot (Quintals per Bigha)}

\begin{tabular}{|l|c|c|}
\hline & $\begin{array}{c}\text { Plots with own } \\
\text { tubewell }\end{array}$ & $\begin{array}{c}\text { Plots with purchased } \\
\text { water }\end{array}$ \\
\hline Overall & 59 & 53 \\
\hline Sandy loam soils & 59 & 52 \\
\hline Loam soils & 58 & 58 \\
\hline
\end{tabular}

Conversion: Rs.50=\$1; 1 bigha $=0.2$ acres; 1 quintal=100 kg.

Table 2: Summary Statistics of Other Inputs and Output Variables (326 observations)

\begin{tabular}{|c|c|c|c|c|}
\hline Variable & Mean & Standard Deviation & Min & Max \\
\hline Output (quintals) & 443 & 430.16 & 30 & 4000 \\
\hline Plot Area (bighas) & 7.5 & 6.2078 & 1 & 50 \\
\hline Labor (hours) & 1302 & 1189.12 & 178 & 9190 \\
\hline Manure (quintals) & 116 & 228.42 & neg & 2520 \\
\hline Fertilizers (value) & 1704.2 & 1686.36 & neg & 10915 \\
\hline Tractor(hours) & 7.9 & 22.15 & neg & 200 \\
\hline Oxen(hours) & 86.4 & 99.617 & 5.2 & 568 \\
\hline $\begin{array}{c}\text { Irrigation (bigha- } \\
\text { inches) }\end{array}$ & 222.5 & 208.59 & & 1330 \\
\hline
\end{tabular}

Conversion: 1 bigha $=0.2$ acres. 1 bigha-inch $=20.6$ cubic meters. 
Table 3. Cobb-Douglas Production Function Estimates (Variables in logs)

\begin{tabular}{|c|c|c|c|}
\hline Output & Coefficient & Standard Error & t-ratio \\
\hline Plot Area & $0.742^{* * *}$ & 0.0444 & 16.71 \\
\hline Labor & $0.076^{* * *}$ & 0.0287 & 2.65 \\
\hline Manure & 0.001 & 0.0060 & 0.23 \\
\hline Fertilizers & -0.028 & 0.0177 & -1.58 \\
\hline Tractor & $0.091^{* * *}$ & 0.0176 & 7.14 \\
\hline Oxen & $0.125^{* * *}$ & 0.0177 & 2.61 \\
\hline Irrigation & $0.064^{* * *}$ & 0.0246 & 11.70 \\
\hline Crop Dummy & $0.486^{* * *}$ & 0.0416 & \\
\hline Farmer Dummies & $* *$ and $* * *$ & & 17.13 \\
\hline Constant & $2.996^{* * *}$ & & \\
\hline
\end{tabular}

Other information on the Cobb-Douglas Estimation: Number of Observations: 326; F(16,309) = 396.47; Prob $>\mathrm{F}=$ 0.0000; R-squared=0.9536; Adjusted R-squared $=0.9511 . * *$ and $* * *$ denote $5 \%$ and $1 \%$ levels of significance.

Table 4A. Estimates for Marginal Value Product of Water (MVPW) (Incremental Rs. per Incremental Bigha-Inch), with 95\% Confidence Intervals; Water Price (Rs. per Bigha-Inch)

\begin{tabular}{|c|c|c|c|c|c|c|}
\hline Variable & $\begin{array}{c}\text { Plot Type } \\
\text { (irrigated by } \\
\text { own/joint } \\
\text { TW/bought } \\
\text { water) }\end{array}$ & Observations & $\begin{array}{c}\text { Mean* } \\
\text { (in Rs.) }\end{array}$ & Std. Dev. & Min & Max \\
\hline MVPW & All & 326 & 16.63 & 25.753 & 4.455 & 91.902 \\
\hline Conf. int: R & All & 326 & 16.67 & 25.800 & 4.466 & 92.086 \\
\hline Conf. int: L & All & 326 & 16.60 & 25.705 & 4.444 & 91.729 \\
\hline Water Price & All & 326 & 6.53 & 2.12 & 2.77 & 13.64 \\
\hline
\end{tabular}

*: After dropping 2 outliers. Conf. int. $\mathrm{L}$ and $\mathrm{R}$ are left and right endpoints of confidence intervals. TW=tubewell. Conversion: Rs.50=\$1. 1 bigha-inch $=20.6$ cubic meters.

Table 4B. Mean Marginal Value Product of Water by Plot Type

\begin{tabular}{|l|l|c|}
\hline Variable & Plot Type & Mean \\
\hline MVPW & Own TW & 11.872 \\
\hline Conf. int: R & Own TW & 11.899 \\
\hline Conf. int: L & Own TW & 11.844 \\
\hline MVPW & Buy water & 18.434 \\
\hline Conf. int: R & Buy water & 18.476 \\
\hline Conf. int: L & Buy water & 18.392 \\
\hline
\end{tabular}

Conf. int. $\mathrm{L}$ and $\mathrm{R}$ are left and right endpoints

of confidence intervals. TW=tubewell 
Table 5. (Section IV): What Would be Profits and Output from the Sample Plots if the Total Observed Water From each Tubewell in the Sample is Allocated Efficiently Across the Plots that are Serviced by that Tubewell?

\begin{tabular}{|l|c|c|c|}
\hline Plot Category & $\begin{array}{c}\text { Sample Yield } \\
\text { (Average) }\end{array}$ & $\begin{array}{c}\text { Simulated Change } \\
\text { (yield) }\end{array}$ & $\begin{array}{c}\text { Simulated } \\
\text { Change (value) }\end{array}$ \\
\hline All Plots & 58.22 & +0.18 & +18.36 \\
\hline Plots with Single-Owner TW & 59.17 & -0.04 & -4.08 \\
\hline Plots that bought water & 53.58 & +1.0 & +102.0 \\
\hline
\end{tabular}

Yield = quintals of sugarcane per bigha; Value = Rs. per bigha; Sample Area=2350 bighas. $T W=$ tubewell . Conversion: 1 quintal=100kg. Rs.50=\$1. 1bigha $=0.2$ acres.

Table 6. Policy Simulation: Effect of Unit Power Price on Yields, Irrigation Volumes, Profits

\begin{tabular}{|c|c|c|c|c|}
\hline $\begin{array}{c}\text { Power Price } \\
\begin{array}{c}\text { (sample: zero unit } \\
\text { price) }\end{array}\end{array}$ & Yield & Profits & Irrigation Volume & Power Revenue \\
\hline 1.8 & 58.22 & $\begin{array}{c}2490.56 * \\
(2220.56)\end{array}$ & 30.02 & $\begin{array}{c}270.31^{*} \\
(540.31)\end{array}$ \\
\hline 2.1 & 63.6051 & 2655.8063 & 34.6596 & 386.2131 \\
\hline 2.3 & 63.4592 & 2596.2295 & 33.5920 & 437.3032 \\
\hline 2.5 & 63.2845 & 2552.9979 & 33.0832 & 472.3410 \\
\hline 2.7 & 63.2084 & 2514.1835 & 32.6242 & 506.6724 \\
\hline 2.9 & 63.0827 & 2472.6266 & 32.2906 & 542.3565 \\
\hline 3.1 & 63.0196 & 2434.2964 & 31.9595 & 576.9297 \\
\hline 3.3 & 62.9608 & 2396.2129 & 31.6714 & 611.5009 \\
\hline 3.5 & 62.5901 & 2342.0245 & 31.1676 & 643.0514 \\
\hline 3.7 & 62.5433 & 2304.4084 & 30.9738 & 677.8705 \\
\hline 3.9 & 61.7818 & 2231.8122 & 30.5666 & 708.5204 \\
\hline 4.1 & 61.0862 & 2163.0638 & 30.4730 & 744.6356 \\
\hline 4.3 & 61.0602 & 2125.6163 & 30.3827 & 780.5405 \\
\hline 4.5 & 61.0355 & 2088.2412 & 30.3008 & 816.4444 \\
\hline & 61.0120 & 2050.9319 & 30.2262 & 852.3476 \\
\hline
\end{tabular}

Units: Power Price: Rs. per kilowatt hour; Yield: Quintals per bigha; Profits: Rupees per bigha Irrigation Volume: bigha-inches (per bigha); Power Revenue: Rs. per bigha.

Conversion: Rs. 50=\$1; 1 bigha $=0.2$ acres; 1 bigha-inch=20.6 cubic meters. The sample profits and power revenue per bigha are starred, as profits are higher and power revenue lower due to farmers underreporting the horsepower of their pumps. Correct reporting would result in the profits and power revenue given in parentheses, below the starred levels in row 1. 